JPP) Jurnal Kesehatan Poltekkes Palembang

Vol. 14, No. 1, Juni 2019, eISSN 2654-3427

\title{
ANALISIS HASIL BELAJAR MAHASISWA D III KEBIDANAN PADA MATA KULIAH ASUHAN KEBIDANAN III (NIFAS) DI SEKOLAH TINGGI ILMU KESEHATAN PALEMBANG
}

\section{ANALYSIS OF STUDENTS LEARNING OUTCOMES MIDWIFERY DIPLOMA ON MIDWIFERY CARE LESSON AT HIGH COLLEGE OF HEALTH SCIENCE PALEMBANG}

\author{
Nora Novia Vinnata \\ Fakultas Ilmu Kesehatan, Universitas Katolik Musi Charitas Palembang, Sumatera Selatan, Indonesia \\ (email penulis korespondensi: norariyan.nn@gmail.com)
}

\author{
Info Artikel: Diterima: 01 April $2019 \quad$ Revisi: 21 Mei $2019 \quad$ Diterima: 01 Juni 2019
}

\begin{abstract}
ABSTRAK
Latar Belakang:Setiap program belajar mengajar mempunyai tujuan untuk meningkatkan tujuan pendidikan. Dalam proses pendidikan tersebut partisipasi guru sebagai pendidik dan siswa sebagai peserta didik sangat dibutuhkan. Dengan kata lain kegiatan belajar mengajar, komponen guru dan siswa sangat diperlukan dalam kegiatan tersebut. Penelitian ini bertujuan untuk mengetahui faktorfaktor yang berhubungan dengan hasil belajar mahasiswa.

Metode:Penelitian ini menggunakan metode analitik dan pendekatan Cross Sctional dengan populasi dalam penelitian ini adalah semua mahasiswa tingkat II di STIKES Mitra Adiguna Palembang dan sesuai dengan kartu hasil study (KHS) mahasiswa tingkat II semester III tahun 2010 pada Mata Kuliah Asuhan Kebidanan III (Nifas) yaitu sebanyak 97 mahasiswa.

Hasil: hasil penelitian univariat menunjukan bahwa proporsi hasil belajar baik sebanyak 69 responden $(71,1 \%)$, sikap mahasiswa positif sebanyakk 75 responden $(77,3 \%)$, minat mahasiswa positif sebanyak 69 responden $(71,1 \%)$, pendidikan orang tua tinggi sebanyak 74 responden $(76,3 \%)$, hasil uji statistik menunjukan bahwa ada hubungan bermakna antara sikap ( $\mathrm{p}$ value 0,001 ), minat mahasiswa( $p$ value 0,002$)$ dan pendidkan orang tua ( $p$ value 0,002$)$ dengan hasil belajar.

Kesimpulan: Berdasarkan hasil penelitian yang telah dilakukan ada hubungan yang bermakna antara sikap mahasiswa, minat mahasiswa dan pendidikan orang tua dengan hasil belajar mahasiswa

Kata Kunci: Hasil Belajar, Mahasiswa Kebidanan, Asuhan Kebidanan

ABSTRACT:

Background:Every learning process has the objective to improve educational purposes. In this education process teachers participation as educators and students as learners is needed. In other words, learning activities, teacher and student are necessary in these activities.

Methods:The objective of this study to know the factors related with student learning outcomes. The method of this study was analytic and approaches cross sectional methods. The population of this study were all the second grade students in STIKES Mitra Adiguna Palembang and based on the learn outcomes card the second grade semester II of 2010 are 97 students. The results showed that the univariate results that the proportion of good learning outcomes as much as 69 respondents (71.1\%), positive student attitudes as much as 75 respondents (77.3\%), positive student interest as much as 69 respondents (71.1\%), education parental height by 74 respondents (76.3\%).The results of the best statistics show that there is a significant relationship between attitudes, interests and education of parents of students with learning outcomes, where the attitude variables obtained ( $p$ value 0.001), the variable interest $p$ value $0.002<0.05$, and parental education variables ( $p$ value 0.002 ).
\end{abstract}

Keywords: Learning Outcomes, Midwifery students, Midwifey care 


\section{PENDAHULUAN}

Setiap proses belajar mengajar mempunyai tujuan untuk meningkatkan tujuan pendidikan. Dalam proses pendidikan tersebut partisipasi guru sebagai pendidik dan siswa sebagai peserta didik sangat dibutuhkan. Dengan kata lain kegiatan belajar mengajar, komponen guru dan siswa sangat diperlukan dalam kegiatan tersebut. Hal terpenting dalam proses belajar mengajar adalah proses belajar yang terjadi dalam pikiran siswa. Selain menerima materi yang diberikan oleh guru, siswa diharapkan lebih aktif dalam melakukan kegiatan dalam proses pembelajaran seperti membaca, diskusi, kerja kelompok, belajar dari materi-materi lain dan mengerjakan atihan, sehingga mereka lebih aktif dan termotivasi untuk belajar. ${ }^{5}$

Kualitas dosen dan mahasiswa sangat penting dalam meraih prestasi, kelengkapan sarana dan prasarana tanpa disertai kinerja yang baik dari para penggunya akan sia-sia saja. Bila tenaga pengajar mengajar dengan arif, bijaksana, tegas, memiliki disiplin tinggi, luwes dan mampu membuat mahasiswa menjadi senang akan pelajaran, maka prestasi belajar mahasiswa cenderung tinggi. ${ }^{9}$

Salah satu faktor dalam diri mahasiswa yang menentukan berhasil tidaknya mahasiswa dalam proses belajar mengajar adalah motivasi belajar. Dalam kegiatan belajar, motivasi merupakan keseluruhan daya penggerak didalam diri mahasiswa yang menimbulkan kegiatan belajar yang menjamin kelangsungan dari kegiatan belajar. Motivasi mempunyai peranan penting dalam proses belajar mengajar baik dari dosen maupun mahasiswa. Bagi dosen mengetahui motivasi belajar dari mahasiswa sangat diperlukan guna memelihara dan meningkatkan semangat belajar sehingga mahasiswa terdorong untuk melakukan perbuatan belajar. ${ }^{1}$

Selain motivasi faktor internal yang dapat mempengaruhi hasil belajar mahasiswa adalah minat. Minat besar pengaruhnya terhadap belajar karena bila bahan pelajaran yang dipelajari tidak sesuai dengan minat mahasiswa maka mahasiswa tidak akan belajar dengan sebaik-baiknya. Dalam proses belajar harus diperhatikan apa yang dapat mendorong mahasiswa agar dapat belajar dengan baik serta mempunyai motivasi untuk berfikir dan memusatkan perhatian. ${ }^{8}$

Sedangkan faktor dari luar dari mahasiswa yang dapat mempengaruhi potensi belajar adalah faktor pendidikan orang tua. Orang tua yang telah menempuh jenjang pendidikan tinggi cenderung lebih memperhatikan dan memahami pentingnya pendidikan bagi anak-anaknya, dibandingkan dengan yang mempunyai jenjang pendidikan lebih rendah. ${ }^{11}$

Kegiatan proses belajar mahasiswa Akademi Kebidanan mengacu pada kurikulum DIII Kebidanan Tahun 2002 untuk mahasiswa Tingkat II semester III mata kuliahnya adalah Farmakologi, Ginekologi, Gizi dalam Kesehatan Reproduksi, ASKEB II (Persalinan), ASKEB III (Nifas), Asuhan Neonatus, Bayi dan balita, Dokumentasi Kebidanan, Promosi Kesehatan. Dari mata kuliah tersebut mata kuliah asuhan kebidanan II merupakan mata kuliah pokok yang menjadi dasar karena jumlah SKS terdiri dari teori 1 SKS dan praktek 3 SKS nilai minimal kelulusannya adalah 56 .

Berdasarkan data di atas maka penulis tertarik untuk melakukan penelitian dengan judul "Analisis Faktor-Faktor Yang Berhubungan Dengan Hasil Belajar Mahasiswa Tingkat II Semester III Pada Mata Kuliah Asuhan Kebidan II (persalinan) di STIKES Mitra Adiguna Palembang"

\section{METODE}

Penelitian ini dilakukan di STIKES Mitra Adiguna Palembang pada bulan Juni-Juli Tahun 2011,sampel dalam penelitian ini mengambil total populasi yaitu semua mahasiswa tingkat II Semester IV STIKES Mitra Adiguna Palembang Tahun 2011yang terbagi menjadi dua kelas yaitu pada tingkat II A berjumlah 49 orang dan tingkat II B berjumlah 48 orang sehingga seluruh total populasi berjumlah 97 orang. Selanjutnya data diolah dengan menggunakan metode survei analitik dan teknik analisis data yang digunakan secara analisa univariat dan analisa bivariat dengan uji statistik Chi-Square dengan batas kemaknaan yaitu $\alpha(0,05)$. Teknik pengumpulan data dengan cara wawancara menggunakan angket dan data sekunder (dari Kartu Hasil Studi (KHS) dan profil Akademi. 


\section{HASIL}

Berdasarkan Tabel 1 diketahui bahwa dari 97 responden mahasiswa pada hasil belajar dalam kategori baik sebanyak $(71,1 \%)$ dan hasil belajar kurang sebanyak $(28,9 \%)$, sikap mahasiswa positif sebanyak $(77,3 \%)$ lebih besar dibanding mahasiwa negatif $(22,7 \%)$, minat mahasiswa positif sebanyak $(71,1 \%)$ lebih besar dibanding mahasiswa negatif $(28,9 \%)$ dan pendidikan orang tua tinggi $(76,3 \%)$ lebih besar dibanding pendidikan orang tua rendah $(28,9 \%)$.

Tabel 1. Hasil Analisis Univariat $(n=97)$

\begin{tabular}{llc}
\hline Variabel & n & $\begin{array}{c}\text { Persentase } \\
(\%)\end{array}$ \\
\hline Hasil Belajar & & \\
$\quad$ 1. Baik & 69 & 71,1 \\
2. Kurang & 28 & 28,9 \\
Sikap Mahasiswa & & \\
$\quad$ 1. Positif & 75 & 77,3 \\
2. Negatif & 22 & 22,7 \\
Minat Mahasiswa & & \\
$\quad$ 1. Positif & 69 & 71,1 \\
2. Negatif & 28 & 28,9 \\
Pendidikan Orang Tua & & \\
$\quad$ 1. Tinggi & 74 & 76,3 \\
2. Rendah & 23 & 23,7 \\
\hline
\end{tabular}

Tabel 2. Hubungan Antara Sikap, Minat dan Pendidikan Orang Tua Mahasiswa dengan Hasil Belajar ( $\mathbf{n = 9 7 )}$

\begin{tabular}{|c|c|c|c|c|c|c|c|}
\hline \multirow{3}{*}{ Karakteristik } & \multicolumn{4}{|c|}{ Hasil Belajar } & \multirow{3}{*}{$\mathbf{n}$} & \multirow{3}{*}{$\%$} & \multirow{3}{*}{ p value } \\
\hline & \multicolumn{2}{|c|}{ Baik } & \multicolumn{2}{|c|}{ Kurang } & & & \\
\hline & $\mathbf{n}$ & $\%$ & $\mathrm{n}$ & $\%$ & & & \\
\hline \multicolumn{8}{|l|}{ Sikap } \\
\hline \multicolumn{8}{|l|}{ Mahasiswa } \\
\hline 1. Positif & 60 & 80,0 & 15 & 20,0 & 75 & 100 & 0,001 \\
\hline 2. Negatif & 9 & 40,9 & 13 & 59,1 & 22 & 100 & \\
\hline \multicolumn{8}{|l|}{ Minat } \\
\hline \multicolumn{8}{|l|}{ Mahasiswa } \\
\hline 1. Positif & 56 & 81,2 & 13 & 18,8 & 69 & 100 & 0,002 \\
\hline 2. Negatif & 13 & 46,4 & 15 & 53,6 & 28 & 100 & \\
\hline \multicolumn{8}{|l|}{$\begin{array}{l}\text { Pendidikan } \\
\text { Orang Tua }\end{array}$} \\
\hline 1. Tinggi & 58 & 78,4 & 16 & 21,6 & 74 & 100 & 0,010 \\
\hline 2. Rendah & 11 & 47,8 & 12 & 52,2 & 23 & 100 & \\
\hline
\end{tabular}

Pada penelitian ini dilakukan uji statistik bivariat antara variabel independen sikap, minat, dan pendidikan orang tua mahasiswa dengan variabel dependen hasil belajar. Berdasarkan Hasil uji statistik dapat dilihat dengan menggunakan tabel silang atau Crosstab pada tabel 2 dari 69 responden proporsi hasil belajar baik dengan sikap belajar positif $(80,0 \%)$ lebih besar dibandingkan dengan proporsi hasil belajar baik dengan sikap belajar negatif $(40,9 \%)$, dan dari 28 responden proporsi hasil belajar kurang dengan sikap belajar positif $(20,0 \%)$ lebih kecil dibandingkan dengan proporsi minat belajar kurang dengan minat belajar negatif $(59,1 \%)$. 
Dari hasil uji statistik diperoleh $p$ value $0,001<$ 0,05 , hal ini menunjukkan bahwa ada hubungan bermakna antara sikap belajar dengan hasil belajar.

Pada minat belajar mahasiswa positif $(81,2 \%)$ lebih besar dibandingkan dengan proporsi hasil belajar baik dengan minat belajar negatif $(46,4 \%)$, dan dari 28 responden proporsi hasil belajar kurang dengan minat belajar positif $(18,8 \%)$ lebih kecil dibandingkan dengan proporsi minat belajar kurang dengan minat belajar negatif $(53,6 \%)$. Dari hasil uji statistik diperoleh $p$ value $0,002<0,05$, hal ini menunjukkan bahwa ada hubungan bermakna antara minat belajar dengan hasil belajar.

\section{PEMBAHASAN}

Dari hasil penelitian menunjukkan bahwa hasil belajar mahasiswa sebagian besar baik. Faktor internal yang dapat mempengaruhi hasil belajar mahasiswa adalah minat. Minat besar pengaruhnya terhadap belajar karena bila bahan pelajaran yang dipelajari tidak sesuai dengan minat mahasiswa maka mahasiswa tidak akan belajar dengan sebaik-baiknya. ${ }^{8}$ Dalam proses belajar harus diperhatikan apa yang dapat mendorong mahasiswa agar dapat belajar dengan baik serta mempunyai motivasi untuk berfikir dan memusatkan perhatian. ${ }^{9}$ Sedangkan menurut Wahyuningsih, faktor dari luar dari mahasiswa yang dapat mempengaruhi potensi belajar adalah faktor pendidikan orang tua. Orang tua yang telah menempuh jenjang pendidikan tinggi cenderung lebih memperhatikan dan memahami pentingnya pendidikan bagi anak-anaknya, dibandingkan dengan yang mempunyai jenjang pendidikan lebih rendah. ${ }^{12}$

Sebagian besar mahasiswa menunjukkan sikap positif, hasil penelitian ini sesuai dengan penelitian yang dilakukan bahwa hasil belajar pada mata diklat dasar tehnik dimana hubungan sikap terhadap hasil belajar sebesar 0,49 dengan konstribusi $24,39 \%$ dan dari hasil uji korelasi antara sikap dan prestasi belajar adalah sebesar 0,674 artinya hasil belajar tidak sepenuhnya dipengaruhi oleh sikap tetapi juga dipengaruhi oleh faktor lain. ${ }^{3}$ Penelitian serupa dilakukan oleh Supartini, sikap belajar berpengaruh besar terhadap peningkatan hasil belajar siswa sebesar $23 \%$ dan $77 \%$ dipengaruhi oleh faktor-faktor lain. ${ }^{11}$

Hal ini sesuai dengan pernyataan Muhibbin, bahwa sikap yang pasif, rendah diri
Proporsi hasil belajar baik dengan pendidikan orang tua tinggi $(78,4 \%)$ lebih besar dibandingkan dengan proporsi hasil belajar baik dengan pendidikan orang tua rendah $(47,8 \%)$, dan dari 28 responden proporsi hasil belajar kurang dengan pendidikan orang tua tinggi $(21,6 \%)$ lebih besar dibandingkan dengan proporsi minat belajar kurang dengan pendidikan orang tua rendah sebanyak 12 $(52,2 \%)$.Dari hasil uji statistik diperoleh $p$ value $0,010<0,05$, hal ini menunjukkan bahwa ada hubungan bermakna antara pendidikan orang dengan hasil belajar.

dan kurang percaya diri dapat merupakan faktor yang menghambat mahasiswa dalam menampilkan prestasi belajarnya. Sikap adalah kesiapan seseorang untuk bertindak secara tertentu terhadap hal-hal tertentu. Sikap mahasiswa yang positif terhadap pelajaran merupakan langkah awal yang baik dalam proses belajar mengajar dan meningkatkan prestasi belajar. $^{12}$

Dari hasil uji statistik menunjukkan bahwa ada hubungan bermakna antara minat belajar dengan hasil belajar. Dengan demikian hipotesis awal yang menyatakan ada hubungan bermakna antara minat belajar dengan hasil belajar. Hasil penelitian ini sejalan dengan penelitian Casdari menyatakan bahwa ada hubungan yang positif antara minat dengan prestasi belajar siswa dengan koefisien determinan $\left(\mathrm{R}^{2}\right)$ sebesar $0,381 .^{2}$ Penelitian lain menunjukkan bahwa mahasiswa yang mempunyai minat yang baik dan pada uji statistik didapatkan ada hubungan antara minat manusia dengan prestasi belajar pada mata pelajaran kesenian. ${ }^{6}$

Oleh karena itu motivasi mempunyai kaitan yang erat dengan minat contoh siswa yang memiliki minat terhadap mata kuliah tertentu cenderung tertarik perhatiannya dan dengan demikian timbul motivasi untuk mempelajarinya demikian juga sebaliknya jika tidak ada motivasi maka minatnya tidak ada. Minat adalah suatu kemampuan umum yang dimiliki mahasiswa untuk mencapai prestasi yang optimal yang dapat ditunjukan dengan kegiatan belajar. ${ }^{4}$ Untuk menambah minat seorang mahasiswa dalam menerima pelajaran $\mathrm{di}$ kelas diharapkan dapat mengembangkan minat 
untuk melakukannya sendiri. Minat belajar yang telah dimiliki mahasiswa merupakan salah satu faktor yang dapat mempengaruhi hasil belajarnya. Apabila seorang mempunyai minat yang tinggi terhadap suatu hal maka akan terus berusaha untuk melakukan sehingga apa yang diinginkannya dapat tercapai sesuai dengan yang keinginannya.

Hasil penelitian ini menunjukkan bahwa ada hubungan bermakna antara pendidikan orang dengan hasil belajar. Dengan demikian hipotesis awal yang menyatakan ada hubungan bermakna antara pendidikan orang tua dengan hasil belajar terbukti secara statistik. Hasil penelitian ini sejalan dengan penelitian Sulistyaningsih, hubungan antara pendidikan orang tua dengan hasil belajar mahasiswa dapat diketahui bahwa proporsi responden yang memiliki pendidikan orang tua dengan hasil

\section{KESIMPULAN DAN SARAN}

Berdasarkan hasil penelitian yang telah dilakukan ada hubungan yang bermakna antara sikap mahasiswa, minat mahasiswa dan pendidikan orang tua dengan hasil belajar mahasiswa. Perlu ditambahkan metode pengajaran khususnya pada mata kuliah ASKEB III (nifas) dengan menggunakan metode mengajar yang inovatif seperti menggunakan alat peraga serta beri penghargaan jika peserta didik mencapai kesuksesan tertentu (pujian atau hadiah).

\section{DAFTAR PUSTAKA}

1. Auliyawati. 2005. Pengaruh Motivasi, Metode Pembelajaran dan Lingkungan Terhadap Prestasi Belajar Akuntansi Pada Siswa Kelas XI Ilmu Sosial SMU Negeri I Karanganan Klaten. Skripsi. Semarang, Universitas Negeri Semarang.

2. Casdari, Mayis. 2005. Pengaruh Perhatian Orang Tua dan Minat Belajar Dengan Prestasi Belajar.

3. Supartini. 2008. Hubungan Motivasi Belajar Dengan Hasil Belajar Siswa. Skripsi. Jakarta : STKIP Purnama.

4. Hermawan. 2008. Hubungan Antara Bakat, Minat, dan Motivasi Siswa Dengan Prestasi Belajar Pada Mata Diklat Dasar Teknik Mesin.

5. Mun'im, A. 2004. Hubungan Prestasi Belajar Program Diklat Kewirausahaan belajar berkorelasi positif dengan cara mereka mengasuh anak, sementara pengasuhan anak berhubungan dengan perkembangan anak yang berarti semakin tinggi pendidikan orang tua makin baik pula cara pengasuhan anak begitupun sebaliknya. ${ }^{10}$ Hasil penelitian lain menunjukkan bahwa ada hubungan yang bermakna antara pendidikan orang tua dengan prestasi belajar. $^{2}$

Hal ini sesuai dengan kondisi pendidikan orang tua sangat berpengaruh terhadap prestasi belajar anaknya. Orang tua yang menempuh jenjang pendidikan yang tinggi cenderung lebih memperhatikan dan memahami pentingnya pendidikan bagi anak-anaknya sehingga dapat meningkatkan prestasi belajar dibandingkan dengan yang mempunyai jenjang pendidikan yang lebih rendah. ${ }^{13}$

Untuk membangkitkan minat belajar mahasiswa dengan cara memberikan informasi pada anak didik mengenai hubungan antara suatu bahan pengajaran yang lalu atau menguraikan kegunaannya di masa depan bagi anak didik serta memberikan kesempatan kepada anak didik untuk mendapatkan hasil belajar yang baik dengan cara menyediakan linkungan belajar yang kreatif dan kondusif.

dengan Minat Siswa SMK Negeri I Samarunda.

6. Olivetti, Febriana. 2008. Hubungan Antara Motivasi dan Minat Mahasiswa Dengan Evaluasi Hasil Belajar Pada Mahasiswa Semester I Akademi Kebidanan Bangka Belitung Tahun 2008. KTI. Palembang : Universitas Kader Bangsa

7. Purbayanti. 2005. Survei Tentang Minat, Motivasi, dan Prestasi Belajar Pada Mata Pelajaran Kesenian di SLTP N 1 Karangan Kabupaten Tenggalek.

8. SK MENDIKNAS No 232 Tahun 2000 Tentang Rentang Nilai.

9. Slamento. 2003. Evaluasi pendidikan. Jakarta : Rineka Cipta; 
10. Slamento. 2003. Belajar Dan Faktor-Faktor yang Mempengaruhinya. Jakarta : Rineka Cipta.Siswa.

11. Sulistyaningsih, S. 2011. Kesiapan Bersekolah ditinjau dari Jenis Pendidkan Pra Sekolah Anak dan Tingkat Pendidikan Orang Tua. Jurnal Pemikiran dan Penelitian Psikologi.
12. Supartini. 2008. Hubungan Motivasi Belajar Dengan Hasil Belajar Siswa. Skripsi. Jakarta : STKIP Purnama.

13. Syah Muhibbin. 2009. Psikologi Belajar. Jakarta : Rajawali Pers

14. Wahyuningsih, Amalia. Hubungan Antara Kecerdasan Emosional Dengan Prestasi Belajar Pada Siswa Kelas II SMU School Jakarta Timur. Skripsi. Jakarta : Universitas Persada Indonesia; 2004 